\title{
Andrea Lluch (Editora). Desarrollo, políticas públicas e institucio- nes: la experiencia de La Pampa en una visión de largo plazo. Santa Rosa, EdUNLPam, 2017, 256 páginas.
}

\author{
Hernán González Bollo
}

1 a historia de las provincias dejó de ser un subcampo de conocimiento por mérito propio, gracias a una pléyade de investigadores que renuevan día a día las preguntas y las dimensiones de análisis; un claro ejemplo de la redimensión de la problemática regional es la investigación de Susana Bandieri (2005). En el camino, claro, han quedado iniciativas frustradas, como por ejemplo la propuesta de la Academia Nacional de la Historia, a fines de 2004, de editar una colección de historias provinciales que iba abarcar los años 1930-2001 y que finalmente no se concretó.

En tanto unidades político-administrativas, son otro objeto de estudio opacado por el notable impacto historiográfico de la historia social. Su "rehabilitación", sí cabe el término, no es tarea fácil, ya que algunas temáticas examinadas traspasan los límites provinciales o son abordajes interdisciplinarios fronteras adentro. Argentina tiene provincias fundadoras de la nacionalidad y gobernaciones que, luego de injustas demoras (González Bollo, 2010), lograron su estatus provincial en la segunda mitad del siglo XX. Este último caso es el de La Pampa. Precisamente, en esta compilación se entrecruzan las instituciones políticas, la búsqueda de un perfil productivo diversificado y una geografía en la que conviven la feraz pampa húmeda y la extensa patagonia. Todo imbricado con el derrotero de las agencias de promoción, desarrollo y planificación, eje axial del trabajo colectivo, y con la preocupación de dimensionar lo acontecido bajo el prisma de los datos estadístico-censales disponibles y la legislación. Aquí hay fragmentos que permiten entrever, más que otra variante de historia social, una historia cultural sobre la identidad de la elite y la comunidad pampeana, a partir de las expectativas y motivaciones de sus protagonistas más relevantes.

Andrea Lluch coordina la compilación, que se divide en dos partes, Desarrollo, políticas y actores y Desarrollo, bienestar y población; aparte, es la

1 Instituto de Investigaciones Gino Germani-Universidad de Buenos Aires/Consejo Nacional de Investigaciones Científicas y Técnicas. Argentina. Correo electrónico: hgbollo@gmail.com 
responsable del primer capítulo. En las Palabras introductorias, explicita el programa que articula el trabajo colectivo. Hay desasosiego por el peso del sector agropecuario en el Producto Bruto Geográfico (PBG) y decepción en la afirmación sobre la incapacidad de consolidar un sector industrial en el mediano plazo (otros ejemplos provinciales muestran el inagotable y engorroso proceso de promoción industrial), con una audaz apuesta por desentrañar el influjo de la intervención estatal en el desarrollo económico y social. En el camino queda pendiente una definición sobre «desarrollo» que articula este incitante trabajo colectivo. En Políticas públicas, planificación y promoción del desarrollo económico en la provincia de La Pampa (ca. 1955-1976), Lluch advierte sobre la diversidad de motivaciones, actitudes y concepciones alrededor de la búsqueda del desarrollo. Así, bajo el peronismo clásico las buenas intenciones ya están esbozadas (Consejos Asesores, leyes de fomento de radicación industrial y programas de colonización), con la creación, por ejemplo, de la Dirección de Estudios y Obras de Riego (1954). Tiene una línea de continuidad ampliada con la Comisión Técnica Interprovincial del Río Colorado (1957). A partir de entonces, el lamento con la retención del caudal del agua por la provincia de Mendoza (paradojas de esta historia, el embalse del Nihuil lo capitalizó como propio la planificación militar-peronista) gira a las altas expectativas de desarrollo del área del río Colorado, junto con Neuquén y Río Negro. De este giro surge la pregunta obvia: en qué medida la retención de buena parte del caudal del río Atuel y la sangría demográfica fueron los impulsores de la "larga marcha" hacia el sudoeste. Y el desarrollismo y la Unión Cívica Radical del Pueblo suman más acción política, de la mano de Ismael Amit, con la formulación de planes de gobierno (iniciativa que sobrevive al golpe de junio de 1966 y más allá). Lluch observa entre tanto optimismo, leyes y decretos de promoción ecos del diagnóstico de la década de 1940, lo cual sugeriría un discurso más o menos homogéneo de las elites.

El capítulo de Federico Martocci, Las políticas estatales para el agro pampeano entre 1953 y 1973: iniciativas oficiales, formación de recursos humanos e investigación científica, comparte muchas de las sugestiones de Lluch $y$, a la vez, visibiliza las burocracias y los expertos. La tesis que articula su trabajo es que al momento de la creación del Instituto Nacional de Tecnología Agropecuaria (INTA) (1956) ya existía una agenda provincial de problemas a resolver e instituciones (las estaciones experimentales) en el área agropecuaria. El imaginario político y técnico mantiene los tópicos clásicos (el atraso en las formas de tenencia de la tierra, la declaración de principios sobre la asistencia al productor, entre otros) con innovaciones institucionales (creación de la Facultad de Agronomía). Existe un contrapunto interesante en el artículo que 
enriquece el debate sobre las iniciativas provinciales y nacionales, entre los NyC ("nacidos y criados") y el "equipo porteño" que arriba de la mano del Poder Ejecutivo Nacional. Aún más interesante es que el desierto argentino revive entre las décadas de 1940 y 1960, con la continua aridez y desertificación, cuyo centro es precisamente La Pampa y se extiende al sur de Córdoba y el oeste de la provincia de Buenos Aires. Sin duda, es un tema fascinante la sequía pampeana, que unas pocas referencias bibliográficas extienden al río Desaguadero, al oeste, y al partido de Junín, al este (Molfino, 1948, 1952; Alazraqui Alonso, 1949).

El discurso del empresariado pampeano en la etapa desarrollista, de Gabriel Grégoire, expone más crudamente lo que hasta ahora es un indicador estadístico, el peso corporativo y la gravitación cultural de los ganaderos, nucleados alrededor de la Asociación Agrícola Ganadera de La Pampa (tan sutiles, que, para no incluir el nombre de la novel provincia "Eva Perón" en la sigla se renombraron "Santa Rosa"). Por extensión, el largo proceso de subdivisión de la tierra pampeana es bajo el dominio de la ganadería vacuna, estimulado por un consumo cárnico que se masifica (rasgo distintivo de la dieta de los argentinos, respecto al resto de América Latina). Esto permite interrogarnos sí las altas expectativas de colonización en el oeste -pasar de 90 colonos asentados a instalar 13.000 familias- no es un deseo compartido con las agencias de promoción y sus expertos provinciales (y sí tal convergencia no señala que debajo de los discursos "desarrollistas" existieron programas soterrados). Mientras el imaginario ganadero tenía las mayores expectativas con la denominada Revolución Argentina, en esta reconstrucción, resulta que la disolución del Ente Provincial del Río Colorado unió a todo el arco empresarial con organizaciones de la sociedad civil. Una buena pregunta es sí aquí tenemos prefigurado las futuras reacciones en todo el país contra la racionalización productiva de Krieger Vasena, un conflicto rápidamente saldado por el poder central con el reemplazo del capitán de navío responsable de tamaña afrenta por un contraalmirante.

La segunda parte, contiene dos artículos, Condiciones y niveles de vida en el interior de Argentina. Territorio Nacional de La Pampa, primera mitad del siglo XX, de Leonardo Ledesma, y Tendencias recientes de las migraciones internacionales en La Pampa: políticas, instituciones y actores, de María Dolores Linares.

Ledesma propone iniciar una cuantificación del estándar de vida de los trabajadores rurales en la primera mitad del siglo XX, a partir de dos alimentos, como son la carne vacuna y la galleta/pan. Los testimonios son elocuentes e indican que la falta de variedad y los escasos ingredientes que componen la 
dieta popular, explican graves casos de pauperismo en La Pampa profunda. A favor de esta tesis, merecen ser destacados los trabajos de Emilio Llorens (1942) y Moisés Poblete Troncoso (1946).

Los relevamientos periódicos de la División Estadística del Departamento Nacional del Trabajo refuerzan esta presunción, la del subconsumo popular, urbano y rural. Y un comentario contenido en el informe de la Armour Research Foundation (1943), que enumera una dieta variada de pan, carne, leche, queso y naranjas, matiza el escenario de avitaminosis propuesto por el gobernador Miguel Duval. Aquí emerge un contrapunto, al menos como hipótesis, sobre la posible variedad de consumo en el centro y noreste pampeano, frente al oeste y sur. Las fuentes de Ledesma son bien exiguas y tiene toda [una] vía de trabajo a reconstruir en las memorias de los Consejos Municipales y la carnicería municipal. De la lectura de las fuentes disponibles parece que en una gobernación eminentemente ganadera no se come carne; y al mismo tiempo, surge la incógnita sobre la disponibilidad de fuentes, tales como, los balances de las haciendas, que debieron computar el consumo de sus trabajadores (advertimos que es un trabajo casi quirúrgico).

Linares, en cambio, nos Ileva a la historia reciente de La Pampa, al abordar las políticas inmigratorias, las instituciones y los actores que intervienen. Desde mediados del siglo XX la normativa oscila entre las amnistías que reconocen el problema de cientos de miles de indocumentados de países limítrofes y la ley 22.439 (1981). Para esta autora, la sanción de la ley 25871 (aprobada en 2004 y reglamentada en 2010) supone una ruptura con las ambigüedades para la circulación y radicación de los inmigrantes. A su vez, esta ruptura sigue un modelo de integración de características asimilacionista y convive con una Dirección Nacional de Inmigraciones anclada en el modelo restrictivo de la ley 22.439. Un gran aporte de Linares es el lote de entrevistas que permiten reforzar la percepción dentro de la Dirección de resistencia al cambio; y más entrevistas a migrantes en Santa Rosa-Toay que refuerzan dos tipos de discriminaciones (negativas y positivas).

En suma, esta compilación reactualiza algunas cuestiones, tales como, la necesidad de acotar el peso de las etapas políticas y redimensionar hitos que jalonan y construyen la historia de La Pampa, continuar con la indagación sobre la génesis y el desarrollo de las expertos provinciales (por ejemplo, la relación entre agencias de promoción provincial y nacional, como CAFADE, INTA, CONADE y CFI) y también sobre el influjo de los ganaderos en el siglo XX. Abre un abanico de preguntas: ¿el Estado pampeano es el único garante y/o responsable del desarrollo? ¿Cuál es el papel del Banco de La Pampa y sus líneas de crédito? ¿Cómo se va configurando la expansión geográfica en esa 
provincia? ¿Cuál es actualmente el papel de los inmigrantes en el desarrollo de las regiones que componen La Pampa? ¿Es posible arribar a estudios comparativos con el desempeño de otras provincias argentinas? Pienso en la cercanía geográfica de San Luis o el influjo de los ganaderos de Santa Cruz, solo contrapesado por la inversión pública, desde fines de la década de 1930. Estas son algunas de las preguntas que suscitan la tarea de investigar el desarrollo de La Pampa.

\section{Referencias bibliográficas}

1. Alazraqui Alonso, J. M. (1949). Colaboraciones acerca de la erosión. Buenos Aires, Argentina, mimeo.

2. Bandieri, S. (2005). Historia de la Patagonia. Buenos Aires, Argentina: Sudamericana.

3. González Bollo, H. (2010). Sobre la amenazante mayoría de dos provincias y una ciudad: los tres primeros censos demográficos y su impacto político en Argentina (1853-1920). Estadística Española, 52 (174), 299-319.

4. Llorens, E. (1942). El subconsumo de alimentos en América del sur. Buenos Aires, Argentina: Sudamericana.

5. Molfino, R. H. (1948). La erosión eólica en la región pampeana y plan para la conservación de los suelos. Buenos Aires, Argentina: Instituto de Suelos y Agrotecnia, Dirección General de Laboratorios e Investigaciones Agrícolas, Ministerio de Agricultura y Ganadería.

6. Molfino, R. H. (1952). Reseña histórica de los trabajos sobre suelos, realizados por el Ministerio de Agricultura, desde su fundación (1898-1948). Buenos Aires, Argentina: Instituto de Suelos y Agrotecnia, Dirección General de Investigaciones Agrícolas, Ministerio de Agricultura y Ganadería.

7. Poblete Troncoso, M. (1946). El subconsumo en América del sur. Alimentos, vestuario y vivienda. Santiago de Chile, Chile: Nascimento. 